\title{
Survey of gastroenterologists on the diagnosis and treatment of adult patients with celiac disease in British Columbia
}

\author{
Hugh J Freeman MD
}

HJ Freeman. Survey of gastroenterologists on the diagnosis and treatment of adult patients with celiac disease in British Columbia. Can J Gastroenterol 1998;12(2):149-152. A recent survey of physician specialists from New York City suggested that few patients with celiac disease are seen and that management experience is limited. The present study, using a survey similar to that of the New York City investigation, evaluated the diagnostic and management experience of specialists for adult celiac disease patients in British Columbia. Four hundred and four patients were reported in the combined clinical practice experience of the responding physicians. Of these, 59 , or $15 \%$, were diagnosed in the prior year. Although each physician diagnosed an average of 2.4 new celiac disease patients per year in their entire practice experience, an average of over 4.0 new celiac disease patients were detected in the past year. Most patients presented with diarrhea, weight loss, anemia or nutrient deficiency, but about $14 \%$ were asymptomatic or diagnosed by an incidental small intestinal biopsy done at upper gastrointestinal endoscopy. Specialist physicians in British Columbia usually refer patients to their family physicians, dietitians and patient support groups for continued care and appear to rarely rely on serological assays, including antibody tests, for detection of celiac disease in adults. An associated or complicating lymphoma was detected in 16 of 404 patients (4\%). Recognition of biopsy-defined celiac disease appears to be increasing in British Columbia.

Key Words: Celiac disease, United States physicians
Sondage auprès des gastro-entérologues sur le diagnostic et le traitement des adultes atteints de sprue cœliaque en Colombie-Britannique

RÉSUMÉ : Un récent sondage auprès des médecins spécialistes de New York donnait à penser que l'on voit peu de patients atteints de sprue cœliaque et que l'expérience thérapeutique ést réduite. L'étude actuelle visait, au moyen d'un sondage semblable, à évaluer l'expérience diagnostique et thérapeutique des spécialistes de la Colombie-Britannique auprès des adultes atteints de sprue cœliaque. Quatre cent quatre patients ont été signalés dans la pratique clinique combinée des médecins répondants. Parmi eux, 59 ou $15 \%$ avaient reçu leur diagnostic au cours de l'année précédente. Bien que chaque médecin ait posé un diagnostic de sprue cœliaque chez 2,4 nouveaux patients par année au cours de leur pratique entière, en moyenne plus de 4,0 nouveaux patients ont été dépistés au cours de l'année passée. La plupart des patients se présentaient pour diarrhée, perte de poids, anémie ou déficit nutritionnel, mais environ $14 \%$ étaient asymptomatiques ou ont reçu leur diagnostic fortuitement, lors d'une biopsie de l'intestin grêle effectuée à l'endoscopie. Les spécialistes de la Colombie-Britannique adressent habituellement leurs patients à leur médecin de famille, à leur diététiste ou à des groupes d'entraide pour la suite des soins et semblent rarement se fier aux dosages sérologiques, y compris aux dosages d'anticorps pour le dépistage de la sprue cœliaque chez l'adulte. Chez 16 patients sur 404 (4\%) on a décelé un lymphome associé ou compliquant le tableau. La reconnaissance de la sprue cœliaque au moyen de la biopsie semble vouloir se répandre en Colombie-Britannique.

Department of Medicine (Gastroenterology), University of British Columbia, Vancouver, British Columbia

Correspondence and reprints: Dr Hugh Freeman, ACU F-137, University Hospital (UBC Site), 2211 Wesbrook Mall, Vancouver,

British Columbia V6T 1W5. Telephone 604-822-7216, fax 604-822-7236

Received for publication October 7, 1997. Accepted January 21, 1998 
$\mathrm{T}$ he prevalence of celiac disease is reported to vary among different geographical centres (1). Recent studies, including one from Italy (2) as well as a European multicentre study (3), suggest that the rates in Europe may be quite high (up to $0.5 \%$, ie, about one celiac disease case per 200 live births). In contrast, celiac disease is believed to be rarer in North America, especially in the United States, although serological surveys for celiac disease in diabetics have suggested that the disease prevalence is similar to that detected in European populations $(4,5)$. Others have suggested that celiac disease, particularly in adults, is simply underdiagnosed in the United States (6). In Canada, there are no accurate data on the prevalence of celiac disease in adults.

In a recent survey of New York City gastroenterologists (7), the number of patients diagnosed with celiac disease and the management patterns of these specialist physicians for patients with diagnosed celiac disease were evaluated. It was concluded that New York City gastroenterologists had few patients with celiac disease in their practices and limited experience in their management.

The present investigation compiled British Columbia gastroenterologists' experiences with celiac disease in adults and compared the results with those from the New York City survey (7). The results suggest that gastroenterologists in British Columbia diagnose more patients with celiac disease in their own referral practices than gastroenterologists from a single urban centre in the United States.

\section{MATERIALS AND METHODS}

A questionnaire on the diagnosis and management of patients with celiac disease was mailed to the 40 listed members of the British Columbia Society of Gastroenterology. This questionnaire was similar in content to a questionnaire used in a New York City survey (7). Of those surveyed in British Columbia, all had completed adult subspecialty training in gastroenterology or its equivalent as defined by the Royal College of Physicians and Surgeons, usually in one of the approved fellowship training programs in Canada, and most physicians practised exclusively in the field of gastroenterology. A small number of physicians in this group also had some hospital role in general internal medicine, often as an associated teaching function or to provide night call coverage in physician groups. One physician practised hepatology almost exclusively (ie, over 95\%), while one physician practised 'hollow-organ' gastroenterology (ie, over 95\%) exclusive of hepatobiliary tract disease.

In British Columbia, diagnosis of celiac disease is based on established and accepted criteria (8). Each gastroenterologist estimated the total number of patients diagnosed with celiac disease in their practice experience as well as the number of patients diagnosed in the past 12 months. In addition, the number of patients initially diagnosed after age 60 years, and the number of patients with celiac disease who had an associated lymphoma or whose disease course was complicated by lymphoma were estimated. As in the New York City survey, the clinical features that prompted initial investigation for celiac disease were explored. These were di-
TABLE 1

Clinical symptoms of celiac patients

\begin{tabular}{lcc}
\hline \multicolumn{2}{c}{ Survey } \\
Clinical feature & British Columbia & New York City \\
\hline Diarrhea & $71 \%$ & $68 \%$ \\
Weight loss & $64 \%$ & $68 \%$ \\
Anemia & $68 \%$ & $71 \%$ \\
Nutrient deficiency* & $43 \%$ & $43 \%$ \\
Other $^{+}$ & $14 \%$ & $11 \%$ \\
\hline
\end{tabular}

*Includes iron deficiency, folic acid deficiency and calcium deficiency; ${ }^{\dagger}$ Includes incidental endoscopic biopsy diagnoses

arrhea, weight loss, anemia, and nutrient deficiency or associated diseases such as dermatitis herpetiformis. In addition, frequency of incidental diagnosis of celiac disease, based on small intestinal biopsy during upper gastrointestinal endoscopy, was evaluated. Management issues were also assessed, including use of serological testing, screening blood tests, bone densitometry studies, repeated small intestinal biopsy after gluten-free diet therapy, screening of first-degree relatives, assessment for hyposplenism and pneumococcal vaccine therapy. Finally, specialist referral to dietitians and celiac support groups was evaluated.

\section{RESULTS}

Survey data: Fourteen surveys (35\%) were returned. Of these, all 14 were from gastroenterologists working with adult patients. This rate of questionnaire return was higher than that in the New York City study; 80 of 400 (20\%) physicians responded to the New York City study, and $98 \%$ of responders were gastroenterologists working with adult patients (7). The range of years in practice in British Columbia was two years to 33 years with a mean of 14.0 years. This was close to the reported clinical practice experience for gastroenterologists in New York City of one year to 50 years with a mean of 17.4 years (7). The 14 physicians from British Columbia estimated the total number of celiac disease patients to be 404. Of these, 142 patients were from one clinical investigative practice. For the other 262 patients, the estimated average number of celiac disease patients seen in clinical practice was just over 20 for each responding gastroenterologist. This was compared with the reported total of 474 patients reported by the $80 \mathrm{New}$ York City gastroenterologists, or about five to six patients for each physician responding to the survey (7).

During the prior year, 33 of $262(13 \%)$ patients were newly diagnosed with celiac disease - an average of 2.5 new patients per physician. In addition, the practice with 142 celiac disease patients diagnosed 26 more new patients for an overall total of 59 new patients diagnosed in British Columbia during the prior year (by the 14 responding physicians), ie, $15 \%$ of 404 patients. This was compared with the New York City experience of 85 new patients diagnosed in the prior year $(18 \%)$ - an average of 1.0 new patient per physician during the prior year (7). Thus, the present study con- 
firms findings of the earlier report (7) that celiac disease appears to be recognized and diagnosed by specialist physicians more frequently than in previous years.

Clinical features: Clinical features that resulted in studies to define celiac disease are summarized in Table 1 . These were compared with the results reported in the New York City survey (7). The majority of patients with celiac disease in British Columbia had diarrhea, weight loss or anemia. A smaller number presented with an isolated nutrient deficiency, such as iron or folic acid deficiency, usually, but not always, with anemia. Only a small number (14\%) were completely asymptomatic and diagnosed incidentally with endoscopic biopsy or during the evaluation of an associated clinical disorder such as dermatitis herpetiformis. As shown in Table 1, these results were similar to those reported in the New York City physician survey (7). Diagnosis of celiac disease was initially established after the age of 60 years in 83 of 404 patients (almost 20\%). Only two of 14 physicians indicated that celiac disease had not been diagnosed in an elderly patient. Overall, eight of the responding physicians reported that 16 of $404 \mathrm{pa}-$ tients (about 4\%) had a malignant lymphoma associated with or complicating the course of their celiac disease.

Management: Table 2 lists some issues related to management of patients with celiac disease. Most specialists in British Columbia tend to direct or self manage patients with celiac disease and refer the patient to their family physician for continuing or ongoing care. This differed from the reported experience in New York City (7) where referral to the family physician was uncommon. This may reflect the requirement in British Columbia for family physicians to refer patients to specialists for investigations and care. Another striking difference was related to the use of serological or antibody testing for celiac disease. Only one specialist physician in British Columbia who responded to this survey performed serological testing (ie, antigliadin antibodies, antiendomysial antibodies) routinely in patients with celiac disease. In contrast, the majority (ie, over $80 \%$ ) of New York physicians performed these serological tests (7). Moreover, serological or biopsy screening of first-degree relatives was rarely reported by any of the responding physicians. Similarly, bone densitometry and repeat baseline blood tests were done only in a minority of celiac disease patients in British Columbia. Small intestinal biopsy after institution of a gluten-free diet was done only in selected patients or in those who did not appear to have an expected clinical response (ie, nonresponders). Hyposplenism was generally defined by most physicians after evaluation of reported peripheral blood smears. If present, pneumococcal vaccine therapy in patients with celiac disease was recommended only by a minority of responding physicians.

Among physicians responding to this survey, all recommended a lifelong gluten-free diet and usually referred patients to a hospital dietitian for further dietary instruction. In general, most physicians provided literature or a recommended source for literature, or review of a video. The majority of specialist physicians also recommended a celiac disease support group.
TABLE 2

Management of celiac disease

\begin{tabular}{lcc}
\hline & \multicolumn{2}{c}{ Survey } \\
Clinical aspect & British Columbia & New York City \\
\hline Self-management & $86 \%$ & $84 \%$ \\
Referral to own medical doctor & $64 \%$ & $16 \%$ \\
Serum antibody tests & $7 \%$ & $84 \%$ \\
Nutrition tests & $100 \%$ & $84 \%$ \\
Bone densitometry & $28 \%$ & $42 \%$ \\
Repeat blood tests & & \\
$\quad$ Annual & $21 \%$ & $38 \%$ \\
$\quad$ Never & $7 \%$ & $77 \%$ \\
Repeat biopsy & & \\
$\quad$ Routine & $7 \%$ & $19 \%$ \\
$\quad$ Selective or nonresponder & $93 \%$ & $59 \%$ \\
$\quad$ Never & - & $10 \%$ \\
Pneumococcal vaccine therapy & $29 \%$ & $36 \%$ \\
Support groups & $86 \%$ & $47 \%$ \\
\hline
\end{tabular}

\section{DISCUSSION}

Based on the data obtained from physicians who responded to this survey, it appears that the frequency of newly diagnosed patients with celiac disease is increasing in British Columbia, with over two new adult cases detected, on average, each month. Assuming that physician respondents from British Columbia and New York City were similar, the present study implies that each specialist physician in British Columbia who responded to the survey had, on average, a greater overall experience in the diagnosis and management of celiac disease than specialists who responded to the survey from New York City (7).

Although demographics of the patient practices from the two geographic areas may not be comparable, readily measurable indexes for each specialist physician, ie, total years in specialty practice as well as mean duration of specialty practice, were similar. In addition, the reported clinical features that resulted in studies for celiac disease were remarkably similar (Table 1). Similar percentages of patients had diarrhea, weight loss or anemia that resulted in studies to detect celiac disease. Moreover, similar percentages of patients with isolated forms of nutrient deficiency, such as iron deficiency, a well known clinical 'trigger' to initiate studies for celiac disease, were identical in the two groups. Finally, similar percentages of patients diagnosed with celiac disease from British Columbia and New York City (14\% versus 11\%) were otherwise asymptomatic or diagnosed following incidental endoscopic small intestinal biopsy. These results suggest that the clinical approach to diagnosis of celiac disease is similar for both specialist physician groups.

There are a number of possible reasons for the apparent differences in detection rates for adult celiac disease between the two countries. Although no specific data are available, the prevalence of celiac disease may be different in the two 
geographic areas. However, no precise data are available from either locale. Alternatively, if the numbers of patients at risk of celiac disease were similar in both geographical areas, diagnostic expertise may differ. Diagnosis of celiac disease in British Columbia is procedure dependent (ie, dependent on small intestinal biopsy), and specialist referral is required. Because there are fewer specialist physicians in British Columbia than in New York City, even on a population basis, the number of patients evaluated by individual specialist physicians in British Columbia is likely greater. This experience might translate into more frequent diagnoses and a greater degree of management experience. However, more data are needed to elucidate this difference.

Management issues were also explored. British Columbia specialists frequently used other community resources for patient management. Most patients were referred to their family physicians as well as to dietitians and celiac support groups. One of the most striking observations in this study was the limited use of serum antibody tests in adult patients with celiac disease. In New York City (7), the vast majority of specialists indicated that serological studies were used. Reasons for this difference are not clear. Serological studies may be used in some centres for screening studies, particularly in higher risk groups such as diabetics, but their value in the diagnosis and management of patients, particularly adults, with already established celiac disease has not been well defined (9). Recent studies from the United States also suggest that consistent results among different commercial test kits are limited - even those from large reference centres (10). More studies are needed to evaluate further the clinical role of these assays in the diagnosis and management of individual celiac disease patients, particularly adults. Possibly, the development of more precise antigen detection methods, such as solid phase ELISA for tissue transglutaminase (11), will permit more consistent screening for celiac disease in large adult populations.

Survey studies of this type have a number of inherent weaknesses. First, the data relied on physician estimates of the patients and their presentations. Second, while the return rate of surveys was greater from gastroenterologists in British Columbia than from those in New York City, both were limited (ie, less than 50\%) and may not reflect the experience of all specialist physicians in either geographic location. Third, about one-third of patients in this survey were based in a single clinical practice. Although this could partially skew the results of the present investigation, major conclusions related to increased recognition of celiac disease in British Columbia confirm the New York City survey results, despite differences in specialist physician practice patterns.

\section{REFERENCES}

1. Trier JS. Celiac sprue. N Engl J Med 1991;325:1709-19.

2. Catassi C, Ratsch IM, Fabiani E, et al. High prevalence of undiagnosed coeliac disease in 5280 Italian students screened by antigliadin antibodies. Acta Paediatr 1995;84:672-6.

3. Greco L, Maki M, Di Donato F, et al. Epidemiology of coeliac disease in Europe and the Mediterranean area. A summary report on the multicentre study by the European Society of Pediatric Gastroenterology and Nutrition. In: Auricchio S, Visakorpi JK, eds. Common Food Intolerances. I. Epidemiology of Coeliac Disease. Basel: Karger, 1992:14.

4. Talal AH, Murray JA, Goeken JA, Sivitz WI. Celiac disease in an adult population with insulin-dependent diabetes mellitus: use of endomysial antibody testing. Am J Gastroenterol 1997;92:1280-4.

5. Rensch MJ, Merenich JA, Lieberman M, Long BD, Davis DR, McNally PR. Gluten-sensitive enteropathy in patients with insulin-dependent diabetes mellitus. Ann Intern Med 1996;124:564-7.

6. Ferguson A. Celiac disease, an eminently treatable condition, may be underdiagnosed in the United States. Am J Gastroenterol 1997;92:1252-4.

7. Poneros JM, Stavropoulos S, Das L, Byfield F, McMahon D, Green PHR. Celiac disease: a physician survey. Gastroenterology 1997;112:A35. (Abst)

8. Freeman HJ. Celiac disease. Contemporary Gastroenterology 1993:1:6-9.

9. Chartrand LJ, Agulnik J, Vanounou T, Russo PA, Baehler P, Seidman EG. Effectiveness of antigliadin antibodies as a screening test for celiac disease in children. Can Med Assoc J 1997;157:527-33.

10. Murray JA, Herlein J, Goeken J. Multicenter comparison of serologic tests for celiac disease in the USA: results of a phase 1 serologic comparison survey. Gastroenterology 1997;112:A389. (Abst)

11. Dieterich W, Ehnis T, Bauer M, et al. Identification of tissue transglutaminase as the autoantigen of celiac disease. Nat Med 1997;3:797-801. 


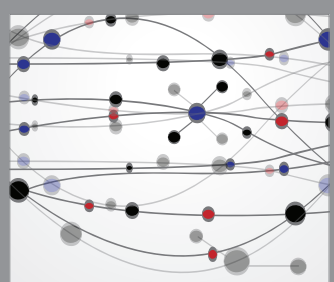

The Scientific World Journal
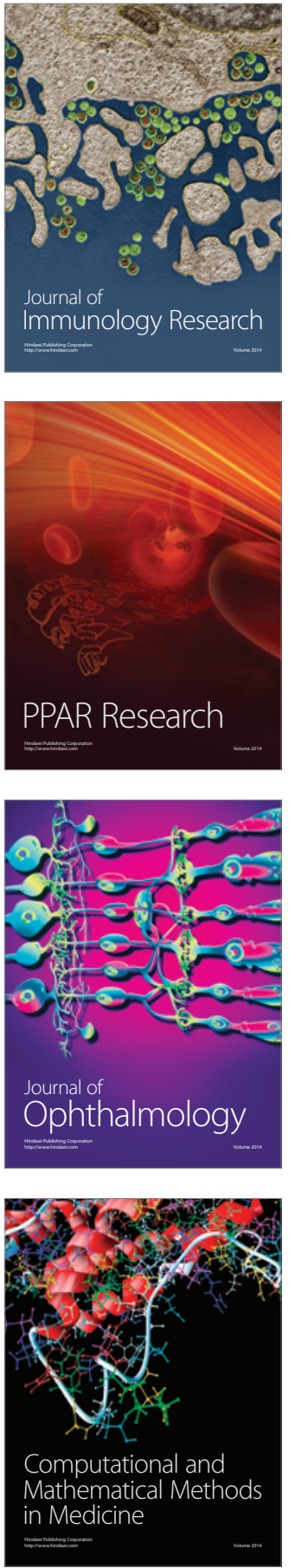

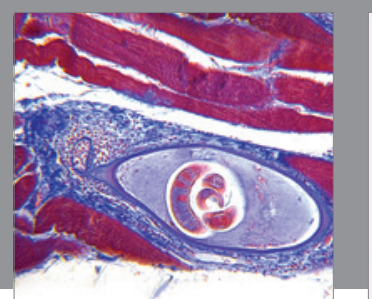

Gastroenterology Research and Practice

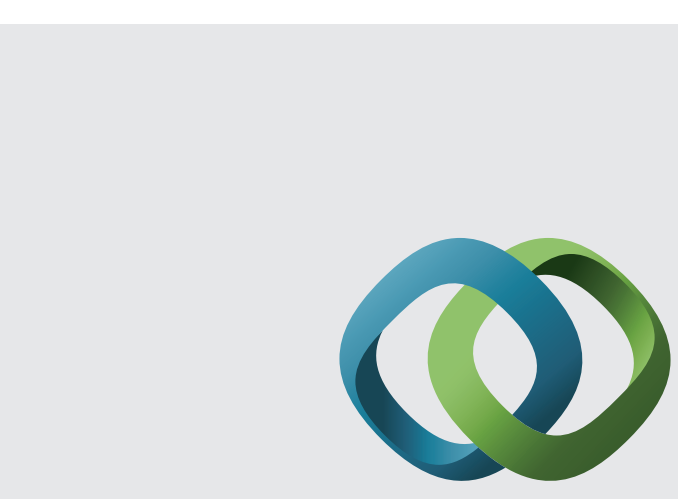

\section{Hindawi}

Submit your manuscripts at

http://www.hindawi.com
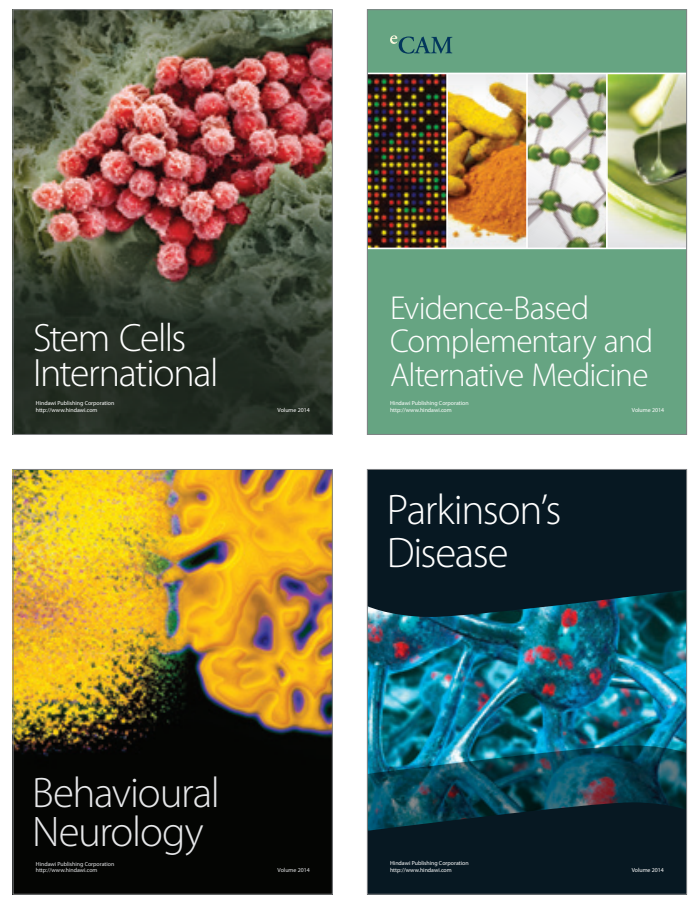
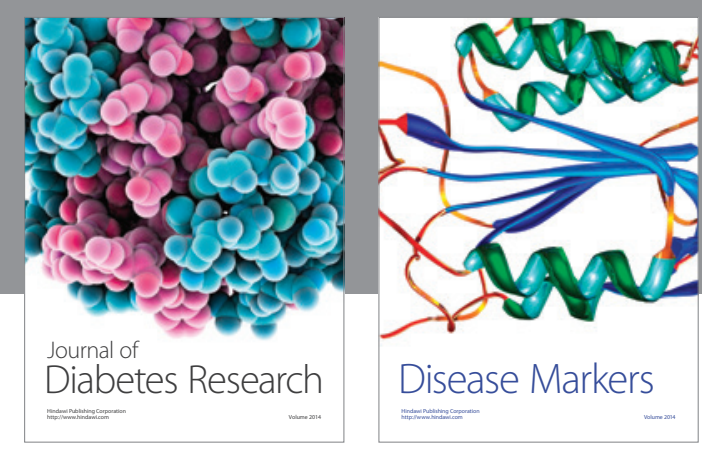

Disease Markers
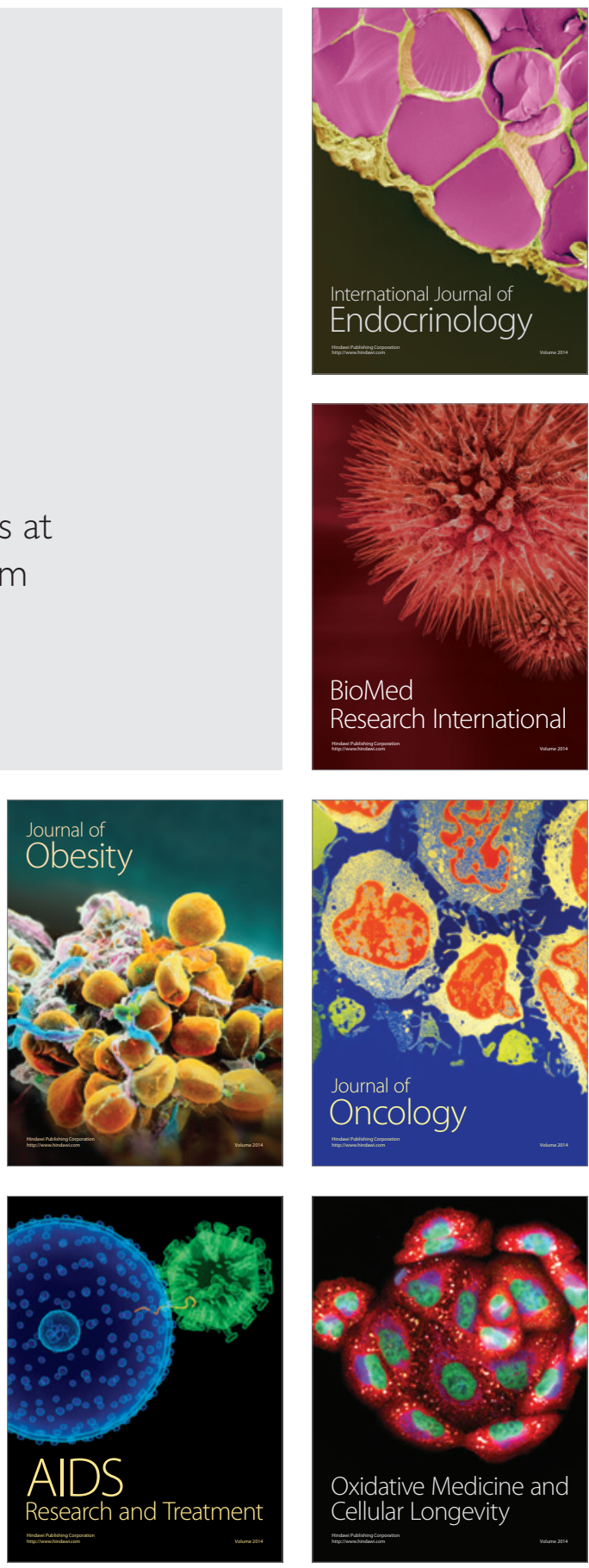